\title{
Mitochondrial haplogroups define two phenotypes of osteoarthritis
}

\author{
Mercedes Fernández-Moreno ${ }^{1}$, Angel Soto-Hermida ${ }^{1}$, Natividad Oreiro ${ }^{1}$, Sonia Pértega ${ }^{2}$, Carlos \\ Fenández-López ${ }^{1}$, Ignacio Rego-Pérez ${ }^{1}{ }^{*}$ and Francisco J. Blanco ${ }^{1,2,3}$ *
}

${ }^{1}$ Rheumatology Division, Genomic Lab Instituto de Investigación Biomédica-Hospital Universitario A Coruña, A Coruña, Spain

${ }^{2}$ CIBER-BBN, Instituto de Salud Carlos III, Madrid, Spain

${ }^{3}$ Departamento de Medicina, Universidad de Santiago de Compostela, Santiago de Compostela, Spain

Edited by:

Alexandrina Ferreira Mendes,

University of Coimbra, Portugal

Reviewed by:

Ali Mobasheri, The University of

Nottingham, UK

Elena N. Dedkova, Rush University

Medical Center, USA

\section{*Correspondence:}

Ignacio Rego-Pérez, Rheumatology

Division, Genomic Lab Instituto de

Investigación Biomédica-Hospital

Universitario A Coruña, 15006-A

Coruña, Spain.

e-mail: ignacio.rego.perez@sergas.es;

Francisco J. Blanco, Osteoarticular and Aging Research Laboratory,

Biomedical Research Center,

Complejo Hospitalario Universitario A

Coruña, 15006-A Coruña, Spain.

e-mail: fblagar@sergas.es
Objective: To assess a mitochondrion-related phenotype in patients with osteoarthritis (OA). Methods: Serum levels of the following OA-related biomarkers: matrix metalloproteinase-1 (MMP-1); MMP-3; MMP-13; myeloperoxidase (MPO); a peptide of the alpha-helical region of type II collagen, Coll2-1, and its nitrated form Coll2-1 $\mathrm{NO}_{2}$; a $\mathrm{C}$-terminal neoepitope generated by the collagenase-mediated cleavage of collagen type II triple helix, C2C; the C-propeptide of collagen type II, CPII; hyaluronic acid (HA); human cartilage glycoprotein 39, YKL-40; cartilage oligomeric matrix protein; and cathepsin $\mathrm{K}$ were analyzed in $48 \mathrm{OA}$ patients and 52 healthy controls carrying the haplogroups $\mathrm{H}$ and $\mathrm{J}$. Logistic regression models and receiver operating characteristic $(\mathrm{ROC})$ curves were performed to predict the onset of OA. Results: MMP-13 was the only biomarker significantly increased in $\mathrm{OA}$ patients compared to healthy controls in both haplogroups $\mathrm{H}$ and $\mathrm{J}$. The collagen type II biomarkers, Coll2-1, Coll2-1 $\mathrm{NO}_{2}$, the Coll2-1 $\mathrm{NO}_{2} / \mathrm{Coll} 2-1$ ratio, C2C, CPII, and the $\mathrm{C} 2 \mathrm{C}$ : $\mathrm{CP}$ II ratio were significantly increased in $\mathrm{OA}$ patients carrying haplogroup $\mathrm{H}$ compared to OA carriers of the haplogroup J. Two logistic regression models for diagnosis were constructed and adjusted for age, gender, and body mass index. For haplogroup $\mathrm{H}$, the biomarkers significantly associated with OA were MMP-13 and Coll2-1; the area under the curve (AUC) of the ROC curve for this model was $0.952(95 \% \mathrm{Cl}=0.892-1.012)$. For haplogroup J, the only biomarker significantly associated with OA was MMP-13; the AUC for this model was $0.895(95 \% \mathrm{Cl}=0.801-0.989)$. Conclusion:The mitochondrial DNA haplogroups are potential complementary candidates for biomarkers of $\mathrm{OA}$; their genotyping in conjunction with the assessment of classical protein molecular markers is recommended.

Keywords: mitochondria, biomarkers, osteoarthritis, cartilage, arthritis

\section{INTRODUCTION}

Osteoarthritis (OA), the most common form of joint disease and cause of musculoskeletal disability in elderly people, is a disease affecting articular cartilage, bone, and soft tissue leading to joint destruction and severe impairment of mobility (Felson and Zhang, 1998). It is the main cause of work incapacity and one of the most common reasons for visiting primary care physicians. Among the risk factors that play a role in OA, gender, age, behavioral influences, obesity, estrogen loss in women and genetic contribution, are notable (Felson and Zhang, 1998; Valdes et al., 2004).

OA is traditionally associated with radiographic signs of joint space narrowing, osteophyte formation, and subchondral sclerosis. Currently, the diagnosis of OA relies on the description of pain symptoms, stiffness in the affected joints and the use of radiography as the reference technique for determining the grade of joint destruction. However, radiographic signs and clinical symptoms only develop in late-stage OA when significant joint damage has already occurred (Cibere et al., 2009). Current treatment strategies are limited, being mainly based on analgesia and, in some cases, surgical procedures (Spil van et al., 2010).
Because OA affects mainly bone, cartilage, and the synovium, structural molecules derived from these tissues could be candidate biological markers for OA. Biomarkers are molecules released into biological fluids during the process of tissue biosynthesis and turnover. The target of the use of biomarkers is to detect changes arising from OA with more reliability, sensitivity, and preferably at an earlier stage of the disease (Garnero et al., 2001, 2002).

With this in mind, several groups have studied potential biomarkers for OA, with sufficiently controversial results that some authors express some limitations about their use as molecular markers for OA (Felson and Lohmander, 2009). Our group proposes new candidate genetic biomarkers, the mitochondrial DNA (mtDNA) haplogroups, which we suggest can be useful as complementary factors when the classical OA-related molecular markers are analyzed.

The mtDNA haplogroups have been associated with several multifactorial diseases, including Alzheimer's (van der Walt et al., 2003), Parkinson's (van der Walt et al., 2004), or Leber hereditary optic neuropathy (LHON; Torroni et al., 1997). Interestingly, we 
detected a lower risk for developing knee and hip OA in carriers of the mtDNA haplogroup J in a Spanish population (Rego-Pérez et al., 2008; Rego et al., 2010) and reported that some of the mtDNA haplogroups are associated with changes in serum levels of several classical OA-related molecular markers (Rego-Pérez et al., 2010, 2011). The proposed mechanism relies on the different metabolic characteristics of these haplogroups, reflected by the performance of the mitochondrial oxidative phosphorylation system (OXPHOS) of each haplogroup (Ruiz-Pesini et al., 2000; Gómez-Durán et al., 2010).

These findings and others strengthen the role of mitochondria in the pathogenesis of OA. A significant decrease in complex II and III activity in OA chondrocytes compared with normal chondrocytes has been demonstrated, and mitochondrial mass was also shown to be increased in OA chondrocytes (Maneiro et al., 2003). The apoptotic mitochondrial pathway has been implicated as one of the major cellular pathways of apoptosis in OA chondrocytes (Kim and Blanco, 2007). In addition, the inhibition of complexes III and V of the mitochondrial respiratory chain (MRC) causes an increased inflammatory response, which is potentially relevant to the production of prostaglandin $\mathrm{E}_{2}\left(\mathrm{PGE}_{2}\right)$ and reactive oxygen species (ROS; Cillero-Pastor et al., 2008). Mitochondrial free radical production has been shown to compromise chondrocyte function (Blanco et al., 2004; Henrotin and Kurz, 2007), causing mtDNA damage and reduced mtDNA capacity for repair (Grishko et al., 2009).

This study aims to assess a mitochondrion-related phenotype in OA patients. Logistic regression models that include the analyses of different OA-related biomarkers, mtDNA haplogroups and other clinical variables OA-related, such as gender, age, and body mass index (BMI) were performed in a population from Northern Spain.

\section{MATERIALS AND METHODS SUBJECTS}

The population analyzed in this study has been previously described (Rego-Pérez et al., 2010). A total of 48 unrelated patients diagnosed with knee or hip OA were included in the present study, 25 carrying haplogroup J and 23 carrying haplogroup H. Patients meeting the inclusion criteria for this study included 32 females and 16 males older than 41 years-old (mean age: $68.48 \pm 7.64$ years-old; range: $52-95$ ), and diagnosed with OA following the American College of Rheumatology (ACR) criteria (Altman et al., 1986). Of the 52 subjects who met the inclusion criteria for normal subjects, 25 carried haplogroup J and 27 haplogroup $\mathrm{H}$. These control subjects included 27 females and 25 males older than 41 years-old (mean age: $66.5 \pm 11.25$ years-old; range: 42-91), who did not meet the ACR criteria for knee or hip OA. Knee and hip radiographs from all 100 subjects were classified according to the Kellgren and Lawrence $(\mathrm{K} / \mathrm{L})$ scoring system, which ranges from Grade 0 to Grade IV (Kellgren and Lawrence, 1957). The clinical variables gender, age, and BMI were collected for all subjects. In all cases, informed consent and the agreement of the ethical committee from Galician Health Administration were obtained.

\section{mtDNA HAPLOGROUPS GENOTYPING}

The samples obtained for the study were haplogroup-typed using a previously described assay (Rego-Pérez et al., 2008). For this study, only subjects carrying mtDNA haplogroups $\mathrm{H}$ and $\mathrm{J}$ were included.

\section{MOLECULAR BIOMARKERS}

Fasting blood samples were collected from each subject in plain tubes containing separation gel. These were allowed to stand for $20 \mathrm{~min}$, then centrifuged for $10 \mathrm{~min}$ at $800 \times \mathrm{g}$. The serum was then divided into aliquots and stored at $-80^{\circ} \mathrm{C}$ pending assay.

For this study the following 12 OA-related molecular markers were measured: metalloproteinase-1 (MMP-1; interstitial collagenase, pro-enzyme), MMP-3 (stromelysin 1, active enzyme), MMP-13 (collagenase 3, active enzyme), myeloperoxidase (MPO), a denaturation epitope of the triple helical domain of collagen type II (Coll2-1) and its nitrated form $\left(\mathrm{Coll2}-1 \mathrm{NO}_{2}\right)$, a C-terminal neoepitope generated by the collagenase-mediated cleavage of collagen type II triple helix (C2C), the procollagen type II C-terminal propeptide (CPII), hyaluronic acid (HA), cartilage glycoprotein 39 (YKL-40), cartilage oligomeric matrix protein (COMP), and cathepsin $\mathrm{K}$, a cysteine protease that also cleaves the triple helix of collagen type II. The determination of MPO, Coll2-1, and Coll2$1 \mathrm{NO}_{2}$ was performed at the Bone and Cartilage Research Unit of the University of Liege (Belgium), using a previously described assay (Deberg et al., 2008). The remaining biomarkers were measured in our laboratory using enzyme-linked immunosorbent assays (ELISAs) according to the manufacturer's recommendations. Serum MMP-1 and MMP-3 levels were measured using kits from R\&D Systems (Minneapolis, MN, USA), MMP-13 was measured using a kit from Bender MedSystems (Vienna, Austria), $\mathrm{C} 2 \mathrm{C}$, and CPII were measured using kits from Ibex Technologies (Montreal, QC, Canada), HA was measured using a kit from Corgenix Medical Corporation (Denver, CO, USA), YKL-40 was measured using a kit from Quidel Corporation (San Diego, CA, USA), COMP was measured using a kit from Abnova (Taipei City, Taiwan) and cathepsin $\mathrm{K}$ was measured using a kit from Biomedica Medizinprodukte (GmbH \& Co KG Vienna, Austria).

The Coll2- $1 \mathrm{NO}_{2} /$ Coll2-1 ratio was utilized as an additional measure of oxidative stress-mediated cartilage degradation, and the $\mathrm{C} 2 \mathrm{C} / \mathrm{CPII}$ ratio as a further index of cartilage breakdown.

The determination of the serum levels of all the biomarkers analyzed in this study was performed by simultaneously assaying $\mathrm{OA}$ patients and healthy controls regardless of mtDNA haplogroup.

\section{STATISTICAL ANALYSIS}

Statistical analyses were performed using SPSS software, release 17 (Chicago, IL, USA), and EPIDAT 3.1 (Dirección Xeral de Saúde Pública. Consellería de Sanidade. Xunta de Galicia. Santiago de Compostela, España). Haplogroups $\mathrm{H}$ and $\mathrm{J}$ were analyzed separately. A univariate analysis was performed on each of these haplogroups to compare serum levels of the biomarkers between OA patients and healthy controls using the Mann-Whitney $U$-test.

Receiver operating characteristic (ROC) curves were used to analyze the ability of different molecular markers to discriminate between OA patients and healthy controls in haplogroups $\mathrm{H}$ and J. The area under the curve (AUC) and its 95\% confidence interval 
were calculated, and only those curves with an AUC $\geq 0.8$ were considered as discriminative. The ROC curves for each of the biomarkers were compared using the method of DeLong et al. (1988).

Multiple logistic regression models adjusted for age, gender, and BMI were used for each haplogroup studied to determine which biomarkers are significantly associated with OA patients (diagnostic model). A forward stepwise approach was followed to construct the final models. The optimal probability cut-off was assessed by maximizing the Youden index (sensitivity + specificity-1). For this cut-off, sensitivity, specificity, and positive likelihood ratio (LR) values were also calculated. The ROC curves resulting from the regression models were developed taking into account only significant variables.

\section{RESULTS}

A total cohort of 100 subjects, 48 OA patients, and 52 healthy controls, were included in this study; 50 were carriers of haplogroup $\mathrm{H}$ and 50 of haplogroup J.

\section{UNIVARIATE ANALYSIS FOR COMPARISON OF THE TESTED MOLECULAR MARKERS}

The mean values for the different molecular markers in each haplogroup, comparing OA patients and healthy controls with their corresponding $p$-values, are shown in Table 1 . The results show that only MMP-13 is significantly increased in OA patients in either haplogroup. Most of the catabolic markers are increased in OA patients who carry haplogroup $\mathrm{H}$, even when compared to OA patients that carry haplogroup J (Table 1; Figure 1). Interestingly, healthy controls carrying haplogroup J show significantly higher levels of MMP-3 and C2C than OA patients with this haplogroup. In summary, these results clearly show a different profile for some of the biomarkers in these two haplogroups.

\section{ROC CURVES FOR THE DIAGNOSIS OF THE MOLECULAR MARKERS}

The ROC curves and their corresponding AUC values for all the biomarkers were calculated. ROC curves were performed for each biomarker in each haplogroup. For carriers of haplogroup $\mathrm{H}$, the most discriminative biomarkers were MMP-13, AUC value 0.869 (95\% $\mathrm{CI}=0.758-0.979), \mathrm{Coll} 2-1 \mathrm{NO}_{2}, 0.863(95 \%$ $\mathrm{CI}=0.756-0.970)$, Colll2- $1 \mathrm{NO}_{2} /$ Coll2-1, 0.836 (95\% CI $=0.719$ 0.953), C2C:CPII, 0.831 (95\% CI $=0.718-0.944)$, and HA, 0.841 (95\% CI $=0.727-0.955$; Table 2). Carriers of haplogroup J had only the MMP-13 biomarker, with an AUC of 0.867 (95\% $\mathrm{CI}=0.749-0.985)$, able to discriminate between OA patients and healthy controls (Table 2).

Because MMP-13 was the most consistent biomarker in all the analyses, a comparison of the ROC curve for MMP-13 and the ROC curves for each of the other biomarkers was performed. For carriers of haplogroup H, the AUC of MMP-13 was statistically different from those of MMP-1 $(p=0.0008)$, C2C $(p=0.0004)$, YKL-40 $(p=0.0017)$, and COMP $(p=0.0040)$. For carriers of haplogroup J, the AUC of MMP-13 was statistically different from MMP-1 $(p=0.0005)$, MPO $(p=0.0104)$, Colll2- $1 \mathrm{NO}_{2} /$ Coll2-1 $(p=0.0039), \mathrm{C} 2 \mathrm{C}$ :CPII $(p=0.0081), \mathrm{HA}$ $(p=0.0049)$, and COMP $(p=0.0015$; Table 2$)$.

\section{MULTIVARIATE LOGISTIC REGRESSION ANALYSIS FOR DIAGNOSIS OF OA}

A model to discriminate between OA patients and healthy controls was developed for each of the two haplogroups to include the clinical variables gender, age, and BMI as well as the tested biomarkers.

After adjusting for age, gender, and BMI, haplogroup $\mathrm{H}$ carriers had biomarkers MMP-13 and Coll2-1 significantly associated with OA (Table 3). The AUC for this model was 0.952 (95\% CI $=0.892-$ 1.012). The optimal probability cut-off for discrimination between OA and healthy subjects was 0.536 , with a sensitivity of $90 \%$, a specificity of $95 \%$, and a positive LR of 18.095 ; thus, the model discriminated very well between OA patients and healthy controls (Figure 2A). In summary, OA patients with haplogroup $\mathrm{H}$ showed higher serum levels of both MMP-13 and Coll2-1 than healthy controls with this haplogroup, as well as an increased BMI and age, regardless of gender.

After adjusting for age, gender, and BMI, patients carrying haplogroup J showed that biomarker MMP-13 was significantly associated with OA (Table 3). The AUC for this model was 0.895 (95\% CI $=0.801-0.989)$. The optimal probability cut-off for discriminating between OA patients and healthy controls was 0.503 , with a sensitivity of $88 \%$, a specificity of $86 \%$, and a positive LR of 6.125 (Figure 2B). In summary, OA patients with haplogroup J showed higher serum levels of MMP-13 than healthy controls with this haplogroup, as well as an increased BMI, regardless of age. This model also showed an increased risk of OA in females (Table 3).

\section{DISCUSSION}

This study was performed to find a mitochondrion-related phenotype in OA patients using the analysis of 12 OA-related molecular markers and two additional ratios, C2C:CPII and Coll2$1 \mathrm{NO}_{2} / \mathrm{Coll2}-1$. As described above, the choice of haplogroups $\mathrm{H}$ and $\mathrm{J}$ was because of the different relationships that our group previously found between the haplogroup $J$ and the prevalence and severity of knee (Rego-Pérez et al., 2008) and hip OA (Rego et al., 2010), and because of the association of haplogroups $\mathrm{H}$ and J with the serum levels of collagen type II markers (Rego-Pérez et al., 2010).

In previous studies, some of the molecular markers found to be increased in OA appeared to show no differences between cases and controls (Rego-Pérez et al., 2010, 2011). This apparent discrepancy may be accounted for by the fact that the serum levels of some of these markers between cases and controls differed depending on the haplogroup carried. In this sense, we found that serum levels of Coll2-1 were (not statistically) increased in healthy controls (Rego-Pérez et al., 2010), contrarily to the findings of other investigators (Deberg et al., 2008); however, the serum levels of Coll2-1 were increased in OA patients with haplogroup $\mathrm{H}$. Even OA patients that carry this haplogroup had also significantly higher serum levels of Coll2- $1 \mathrm{NO}_{2}$ than healthy controls carrying either of the haplogroups $\mathrm{H}$ or $\mathrm{J}$, and also higher than OA patients with haplogroup J (Rego-Pérez et al., 2010). These results were strengthened by measuring the production of Nitric oxide (NO) in articular chondrocytes, showing that carriers of the mtDNA haplogroup J have lower production of $\mathrm{NO}$ 
Table 1 | Univariate analysis of the biomarkers for haplogroups $\mathrm{H}$ and $\mathrm{J}$.

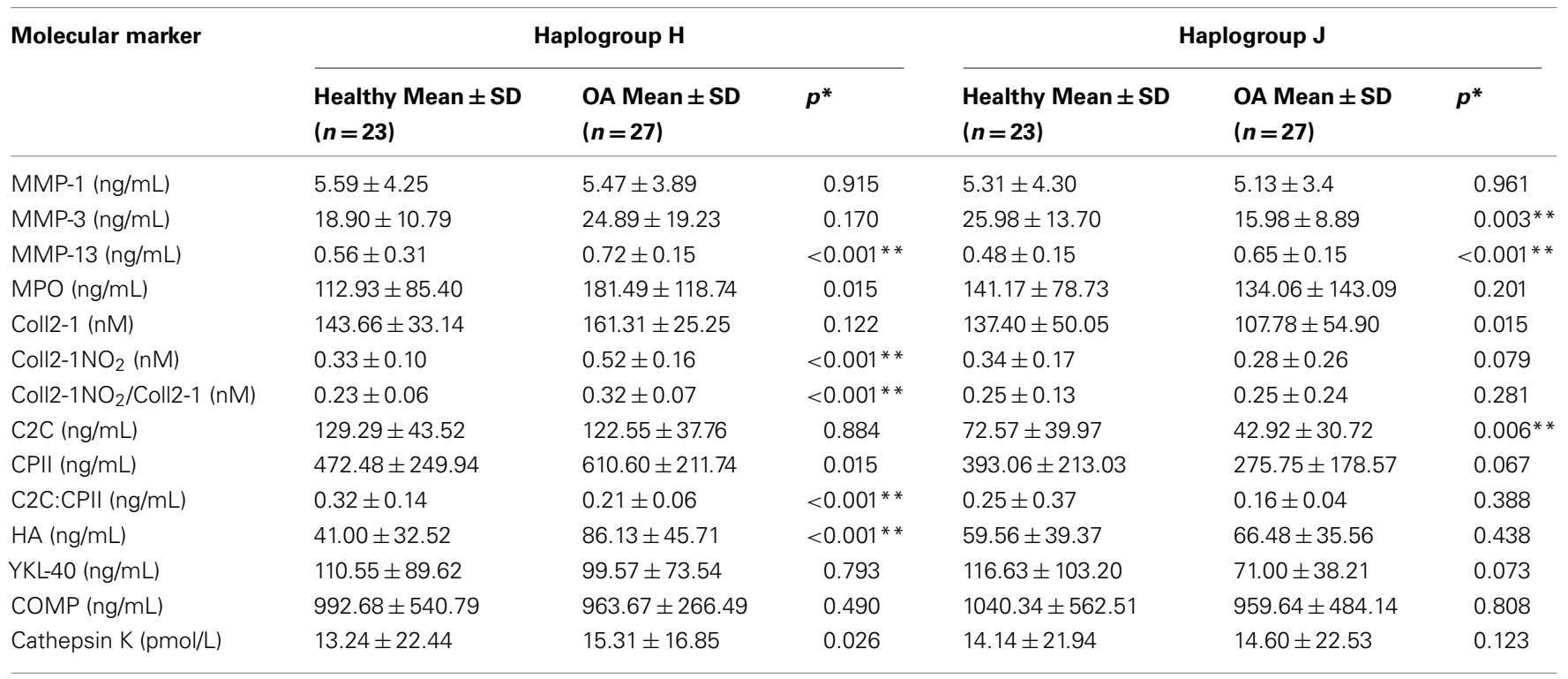

SD, Standard deviation.

*Mann-Whitney non-parametric U-test.

**Statistical significance declared at $p \leq 0.01$ due to multiple comparisons.

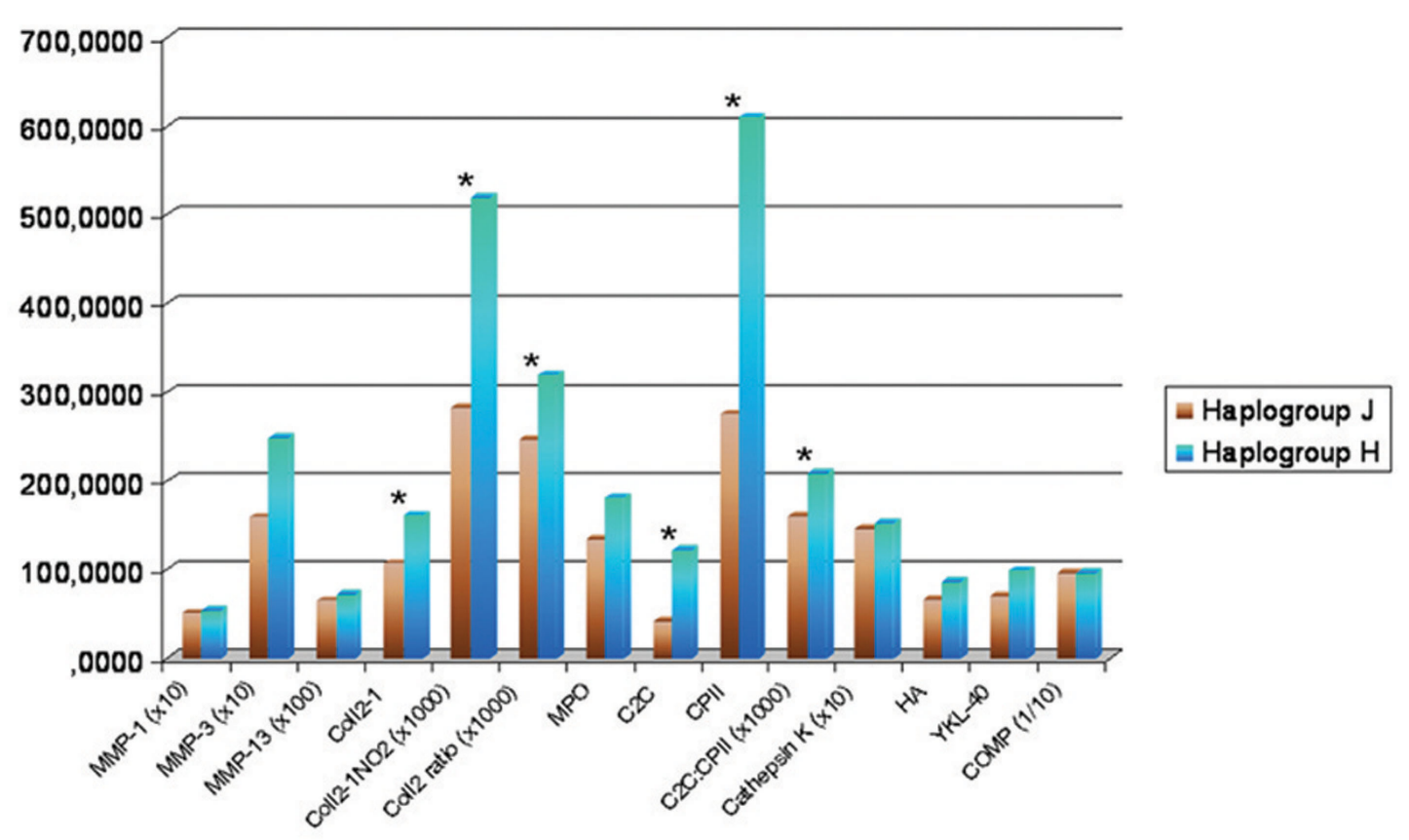

FIGURE 1 | Mean serum levels of osteoarthritis (OA)-related molecular markers in $O A$ patients carrying haplogroup $\mathrm{H}$ and $\mathrm{OA}$ patients carrying the haplogroup $\mathbf{J}$. ( $\left.{ }^{*} p \leq 0.01\right)$; MMP, matrix metalloproteinase; MPO, myeloperoxidase; Coll2-1, denaturation epitope of the triple helical domain of collagen type II and Coll2-1 $\mathrm{NO}_{2}=$ its nitrated form; C2C, a C-terminal neoepitope generated by the collagenase-mediated cleavage of collagen type II triple helix; CPII, the procollagen type II C-terminal propeptide; HA, hyaluronic acid; YKL-40, cartilage glycoprotein 39; COMP, cartilage oligomeric matrix protein. than non-J carriers (Fernández-Moreno et al., 2011). It is known that OA chondrocytes produce NO (Henrotin et al., 1993; Karan et al., 2003) and that the effect of NO on chondrocyte survival is mediated by its effect on the MRC (Maneiro et al., 2005). It is also known that Coll2 $-1 \mathrm{NO}_{2}$ is an indicator of the oxidative stress status of the chondrocyte (Deberg et al., 2008), thereby suggesting that chondrocytes of haplogroup J carriers may have less oxidative stress. 
Table 2 | Comparative analysis of the receiver operating characteristic (ROC) curves of biomarkers for haplogroups $\mathrm{H}$ and $\mathrm{J}$.

\begin{tabular}{|c|c|c|c|c|c|c|}
\hline \multirow[t]{2}{*}{ Molecular marker } & \multicolumn{3}{|c|}{ Haplogroup H } & \multicolumn{3}{|c|}{ Haplogroup J } \\
\hline & AUC & $95 \% \mathrm{Cl}$ & $p^{*}$ & AUC & $95 \% \mathrm{Cl}$ & $p^{*}$ \\
\hline MMP-3 (ng/mL) & 0.614 & $0.457-0.770$ & 0.0185 & $0.747^{\#}$ & $0.609-0.885$ & 0.2001 \\
\hline MMP-13 (ng/mL) & 0.869 & $0.758-0,979$ & & 0.867 & $0.749-0.985$ & \\
\hline MPO (ng/mL) & 0.705 & $0.558-0.851$ & 0.0505 & $0.607^{\#}$ & $0.446-0.767$ & $0.0104 * *$ \\
\hline Coll2-1 $\mathrm{NO}_{2}(\mathrm{nM})$ & 0.863 & $0.756-0.970$ & 0.9465 & $0.645^{\#}$ & $0.484-0.806$ & 0.0279 \\
\hline Coll2-1 $\mathrm{NO}_{2} / \mathrm{Coll} 2-1$ (nM) & 0.836 & $0.719-0.953$ & 0.6711 & $0.589^{\#}$ & $0.425-0.753$ & $0.0039 * *$ \\
\hline $\mathrm{C} 2 \mathrm{C}(\mathrm{ng} / \mathrm{mL})$ & 0.488 & $0.324-0.651$ & $0.0004 * *$ & $0.726^{\#}$ & $0.579-0.874$ & 0.1258 \\
\hline CPII (ng/mL) & 0.700 & $0.552-0.849$ & 0.0662 & $0.651^{\#}$ & $0.497-0.806$ & 0.0162 \\
\hline C2C:CPII (ng/mL) & $0.831^{\#}$ & $0.718-0.944$ & 0.0895 & $0.571^{\#}$ & $0.409-0.733$ & $0.0081 * *$ \\
\hline $\mathrm{HA}(\mathrm{ng} / \mathrm{mL})$ & 0.841 & $0.727-0.955$ & 0.7668 & 0.564 & $0.401-0.727$ & $0.0049 * *$ \\
\hline
\end{tabular}

$A \cup C$, area under the curve. Values in bold indicate the most discriminative $(A \cup C \geq 0.8)$.

Cl, confidence interval.

"Lower values of the biomarker are associated with OA in carriers of this haplogroup.

*Test for homogeneity of areas comparing the AUC from the MMP-13 from those of the other molecular markers.

* Statistical significance declared at $p \leq 0.01$ due to multiple comparisons.

Table 3 | Multivariate logistic regression analysis for diagnosis of osteoarthritis (OA) in haplogroup $\mathrm{H}$ and $\mathrm{J}$ carriers.

\begin{tabular}{|c|c|c|c|c|}
\hline Variables & $B$ & OR & $95 \% \mathrm{Cl}$ & $p^{*}$ \\
\hline \multicolumn{5}{|c|}{ HAPLOGROUP H } \\
\hline Age & 0.263 & 1.301 & $1.026-1.649$ & $0.030 * *$ \\
\hline BMI & 0.647 & 1.910 & $1.124-3.244$ & $0.017 * *$ \\
\hline MMP-13 & 0.430 & 1.537 & $1.023-2.310$ & $0.038^{* *}$ \\
\hline Coll2-1 & 0.104 & 1.110 & $1.013-1.217$ & $0.026^{* *}$ \\
\hline \multicolumn{5}{|c|}{ HAPLOGROUP J } \\
\hline $\mathrm{BMI}$ & 0.404 & 1.499 & $1.062-2.115$ & $0.021^{* *}$ \\
\hline Gender & -1.930 & 0.145 & $0.026-0.816$ & $0.028^{* *}$ \\
\hline MMP-13 & 0.551 & 1.735 & $1.017-2.959$ & $0.043^{* *}$ \\
\hline
\end{tabular}

$B=$ regression coefficient.

OR, odd ratio.

$\mathrm{Cl}$, confidence interval.

${ }^{*} p$-Value from the logistic regression model.

**Statistical significance declared at $p \leq 0.05$.

We believe that the explanation for these discrepant results is related to mtDNA haplogroups. The frequency of distribution of haplogroups in our cohort is substantially different from that observed in typical cohorts, which will follow the distribution of these haplogroups in the general population: haplogroup $\mathrm{H} 40$ 47\% and haplogroup J 7-12\% (Torroni et al., 1996; Dahmany et al., 2006). The frequency distribution in our cohort was the same for each haplogroup. We see that the results derived from the analysis of carriers of haplogroup $\mathrm{H}$, the most common haplogroup in Caucasian populations, are more in line with those obtained by other authors, and reflect the fact that serum levels of most of the catabolic OA-related biomarkers are increased in haplogroup $\mathrm{H}$ carriers, as shown in Figure 1.

In this study, pursuant to the analyses of the ROC curves and univariate analysis, MMP-13 was the only molecular marker that differentiated between $\mathrm{OA}$ patients and healthy controls in carriers of both haplogroups $\mathrm{H}$ and $\mathrm{J}$, as previously described by others (Reboul et al., 1996; Rego-Pérez et al., 2011). In this sense, a role for the mitochondrial dysfunction in the expression of the MMPs has also been proposed (Cillero-Pastor et al., 2008, 2010).

Other molecular markers that have been proposed for differentiating between OA patients and healthy controls, such as HA (Elliott et al., 2005; Mazières et al., 2006), appear to be increased in OA patients, but only significantly increased in haplogroup $\mathrm{H}$ carriers with OA. HA has been reported to be increased in OA patients in some studies and was proposed as a surrogate marker with predictive value for radiographic progression of OA (Mazières et al., 2006; Filková et al., 2009). Our study shows that this association is stronger in haplogroup $\mathrm{H}$ carriers (Table 1). Because the pro-inflammatory cytokine interleukin-1 (IL-1) is one of the main cytokines involved in the mitochondrial dysfunction and in the OA disease, we speculate that this association could be due to different effects of the IL-1, which is an important factor in the synovial production of HA (Nishida et al., 2000), on cells with different mitochondrial backgrounds.

The regression model of diagnosis for haplogroup $\mathrm{H}$ carriers shows that, together with both the BMI and age, those subjects with higher serum levels of MMP-13 and Coll2-1 are more likely to be diagnosed with OA. This model resulted in extraordinary LR and AUC values, hence discriminating very well between OA patients and healthy controls. On the other hand, the model for haplogroup J carriers shows that, together with both the BMI and gender, subjects with higher serum levels of MMP-13 only are more 


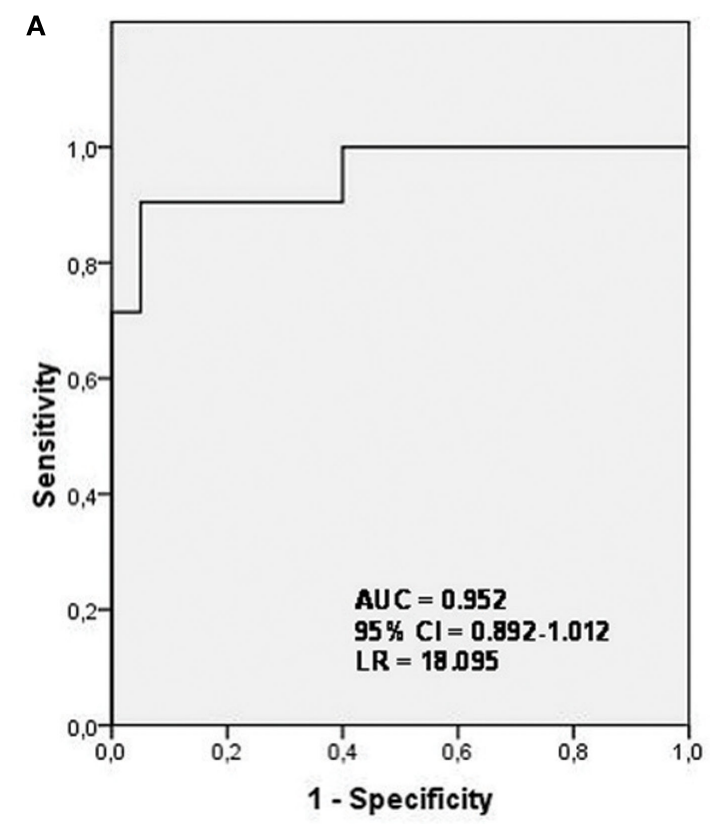

FIGURE 2 | Receiver operating characteristic (ROC) curves derived from the logistic regression models for haplogroups $\mathbf{H}$ and $\mathbf{J}$. (A) ROC

curve from the regression model for diagnosis in haplogroup $\mathrm{H}$ carriers; (B)

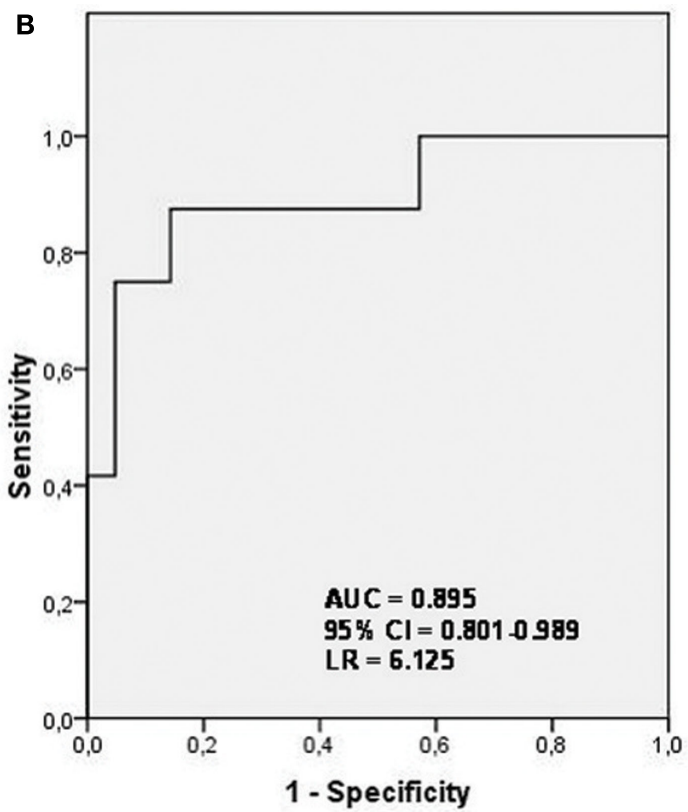

ROC curve from the regression model for diagnosis in haplogroup $\mathrm{J}$ carriers. (AUC, area under the curve; $\mathrm{Cl}$, confidence interval; LR, likelihood ratio). likely to be diagnosed as having OA, therefore do not appearing any other biomarker in this model significantly associated to discriminate between OA patients and healthy controls. In summary, these findings highlight the importance of the mitochondrial background in the OA disease, since Coll2-1 appeared significantly increased in OA patients with the mtDNA haplogroup $\mathrm{H}$, but not in patients with the haplogroup J, probably by the fact that haplogroup $\mathrm{H}$ carriers have more active collagen type II metabolism than haplogroup J carriers do, as proposed in our previous work (Rego-Pérez et al., 2010). Because mtDNA haplogroups $\mathrm{H}$ and J are clearly biochemically different (Wallace, 1999), the possible differences in OXPHOS performance between them (Ruiz-Pesini et al., 2000; Martínez-Redondo et al., 2010) could explain the more active metabolism in haplogroup $\mathrm{H}$ carriers; hence CPII levels in OA patients with haplogroup $\mathrm{H}$ are higher than in healthy controls or OA patients with haplogroup J (Rego-Pérez et al., 2010), which may represent an attempt to repair OA damaged cartilage by increasing the synthesis of collagen type II, as previously described (Aigner et al., 1992; Lohmander et al., 1996; Nelson et al., 1998). Similarly, metabolic differences between these two haplogroups could account for our finding that most of the catabolic collagen type II biomarkers are increased in OA patients who carry haplogroup $\mathrm{H}$, when compared with OA patients who carry haplogroup J.

\section{REFERENCES}

Aigner, T., Stöss, H., Weseloh, G., Zeiler, G., and von der Mark, K. (1992). Activation of collagen type II expression in osteoarthritic and rheumatoid cartilage.
Virchows Arch. B Cell Pathol. 62 337-345.

Altman, R., Asch, E., Bloch, D., Bole, G., Borenstein, D., Brandt, K., Christy, W., Cooke, T. D., Greenwald, R., Hochberg, M., Howell, D., Kaplan,

\section{CONCLUSION}

In summary, the results obtained in this work are of special interest because they strengthen the role of the mitochondrion in the OA process. Either mtDNA haplogroups or an altered mitochondrial function could explain some of the controversial results reported in different studies when analyzing the same biomarkers in different populations of patients. A particular benefit of this study is the notable finding that patients that carry haplogroup $\mathrm{H}$ show higher levels of all the catabolic markers of OA than those OA patients that carry the mtDNA haplogroup J; two different mitochondrionrelated OA phenotypes were clearly defined. Understanding the influence of the mitochondrial background will enable us to detect biomarkers most related to OA, allowing us to design models for haplogroup-based diagnoses.

\section{ACKNOWLEDGMENTS}

This study was supported by grants from Fundación Española de Reumatologia (programa GEN-SER) and from Fondo Investigación Sanitaria (CIBER- CB06/01/0040)-Spain, Fondo Investigacion Sanitaria-PI 08/2028, Ministerio Ciencia e Innovacion PLE2009-0144, with participation of funds from FEDER (European Community). Ignacio Rego was supported by Contrato de Apoyo a la Investigación-Fondo Investigación Sanitaria (CA10/01564).

D., Koopman, W., Longley, S. I. I. I., Mankin, H., Mcshane, D. J., Medsger, T. J. R., Meenan, R., Mikkelsen, W., Mqskowitz, R., Murphy, W., Rothschild, B., Segal, M., Sokoloff, L., and Wolfe, F.
(1986). Development of criteria for the classification and reporting of osteoarthritis: classification of osteoarthritis of the knee. Arthritis Rheum. 29, 1039-1049. 
Blanco, F. J., López-Armada, M. J., and Maneiro, E. (2004). Role of mitochondria and osteoarthritis. Mitochondrion 4, 715-728.

Cibere, J., Zhang, H., Garnero, P., Poole, A. R., Lobanok, T., Saxne, T., Kraus, V. B., Way, A., Thorne, A., Wong, H., Singer, J., Kopec, J., Guermazi, A., Peterfy, C., Nicolaou, S., Munk, P. L., and Esdaile, J. M. (2009). Association of biomarkers with pre-radiographically defined and radiographically defined knee osteoarthritis in a populationbased study. Arthritis Rheum. 60, 1372-1380.

Cillero-Pastor, B., Caramés, B., LiresDeán, M., Vaamonde-García, C., Blanco, F. J., and López-Armada, M. J. (2008). Mitochondrial dysfunction activates cyclooxygenase 2 expression in cultured normal human chondrocytes. Arthritis Rheum. 58, 2409-2419.

Cillero-Pastor, B., Rego, I., LópezArmada, M. J., and Blanco, F. (2010). The dysfunction of mitochondrial respiratory chain regulates the metalloproteinases expression in human normal chondrocytes in culture. Osteoarthr. Cartil. 18, S109.

Dahmany, Y., Marcuello, A., MontielSosa, F. J., Montoya, J., and Sánchez, C. D. (2006). Mitochondrial lineages distribution in the Spanish population: anticipating association studies. Anales de la Real Academia Nacional de Farmacia 72, 37-47.

Deberg, M., Dubuc, J. E., Labasse, A., Sanchez, C., Quettier, E., Bosseloir, A., Crielaard, J.-M., and Henrotin, Y. (2008). One-year follow-up of Coll2-1, Coll2-1 $\mathrm{NO}_{2}$ and myeloperoxidase serum levels in osteoarthritis patients after hip or knee replacement. Ann. Rheum. Dis. 67, 168-174.

DeLong, E. R., DeLong, D. M., and Clarke-Pearson, D. L. (1988). Comparing the areas under two or more correlated receiver operating curves: a nonparametric approach. Biometrics 44, 837-845.

Elliott, A. L., Kraus, V. B., Luta, G., Stabler, T., Renner, J. B., Woodard, J., Dragomir, A. D., Helmick, C. G., Hochberg, M. C., and Jordan, J. M. (2005). Serum Hyaluronan levels and radiographic knee and hip osteoarthritis in African Americans and Caucasians in the Johnston County Osteoarthritis Project. Arthritis Rheum. 52, 105-111.

Felson, D. T., and Lohmander, L. S. (2009). Whither osteoarthritis biomarkers? Osteoarthr. Cartil. 17, 419-422.

Felson, D. T., and Zhang, Y. (1998). An update on the epidemiology of knee and hip osteoarthritis with a view to prevention. Arthritis Rheum. 41, 1343-1355.

Fernández-Moreno, M., Tamayo, M., Soto-Hermida, A., Mosquera, A., Oreiro, N., Fernández-López, C., Fernández, J. L., Rego-Pérez, I., and Blanco, F. J. (2011). mtDNA haplogroup $\mathrm{J}$ modulates telomere length and nitric oxide production. BMC Musculoskelet. Disord. 12, 283. doi:10.1186/1471-2474-12-283

Filková, M., Senolt, S., Braun, M., Hulejová, H., Pavelková, A., Sléglová, O., Kupka, K., Gatterová, J., and Pavelka, K. (2009). Serum hyaluronic acid as a potential marker with a predictive value for further radiographic progression of hand osteoarthritis. Osteoarthr. Cartil. 17, 1615-1619.

Garnero, P., Ayral, X., Rousseau, J. C., Christgau, S., Sandell, L. J., Dougados, M., and Delmas, P. D. (2002). Uncoupling of type II collagen synthesis and degradation predicts progression of joint damage in patients with knee osteoarthritis. Arthritis Rheum. 46, 2613-2624.

Garnero, P., Piperno, M., Gineyts, E., Christgau, S., Delmas, P., and Vignon, E. (2001). Cross sectional evaluation of biochemical markers of bone, cartilage, and synovial tissue metabolism in patients with knee osteoarthritis: relations with disease activity and joint damage. Ann. Rheum. Dis. 60, 619-626.

Gómez-Durán, A., Pacheu-Grau, D., López-Gallardo, E., Díez-Sánchez, C., Montoya, J., López-Pérez, M., and Ruiz-Pesini, E. (2010). Unmasking the causes of multifactorial disorders: OXPHOS differences between mitochondrial haplogroups. Hum. Mol. Genet. 19, 3343-3353.

Grishko, V. I., Ho, R., Wilson, G. L., and Pearsall, A. W. IV. (2009). Diminished mitochondrial DNA integrity and repair capacity in OA chondrocytes. Osteoarthr. Cartil. 17, 107-113.

Henrotin, Y., Deby-Dupont, G., Deby, C., De Bruyn, M., Lamy, M., and Franchimont, P. (1993). Production of active oxygen species by isolated human chondrocytes. Br. J. Rheumatol. 32, 562-567.

Henrotin, Y., and Kurz, B. (2007). Antioxidant to treat osteoarthritis: dream or reality? Curr. Drug Targets 8, 347-357.

Karan, A., Karan, M. A., Vural, P., Erten, N., Tasçioglu, C., Aksoy, C., Canbaz, M., and Oncel, A. (2003). Synovial fluid nitric oxide levels in patients with knee osteoarthritis. Clin. Rheumatol. 22, 397-399.
Kellgren, J. H., and Lawrence, J. S. (1957). Radiological assessment of osteoarthrosis. Ann. Rheum. Dis. 16, 494-502.

Kim, H. A., and Blanco, F. J. (2007). Cell death and apoptosis in osteoarthritic cartilage. Curr. Drug Targets 8, 333-845.

Lohmander, S. Y., Yoshihara, Y., Roos, H., Kobayashi, T., Yamada, H., and Shinmei, M. (1996). Procollagen II c-propeptide in joint fluid: changes in concentrations with age, time after joint injury and osteoarthritis. J. Rheumatol. 23, 1765-1769.

Maneiro, E., López-Armada, M. J., de Andres, M. C., Caramés, B., Martín, M,A., Bonilla, A., del Hoyo, P., Galdo, F., Arenas, J., and Blanco, F, J. (2005). Effect of nitric oxide on mitochondrial respiratory activity of human articular chondrocytes. Ann. Rheum. Dis. 64, 388-395.

Maneiro, E., Martín, M. A., de Andres, M. C., López-Armada, M. J., Fernández-Sueiro, J. L., del Hoyo, P., Galdo, F., Arenas, J., and Blanco, F. J. (2003). Mitochondrial respiratory activity is altered in osteoarthritic human articular chondrocytes. Arthritis Rheum. 48, 700-708.

Martínez-Redondo, D., Marcuello, A., Casajús, J. A., Ara, I., Dahmani, Y., Montoya, J., Ruiz-Pesini, E., LópezPérez, M. J., and Díez-Sánchez, C. (2010). Human mitochondrial haplogroup H: the highest VO2max consumer. Is it a paradox? Mitochondrion 10, 102-107.

Mazières, B., Garnero, P., Guéguen, A., Abbal, M., Berdah, L., Lequesne, M. Nguyen, M., Salles, J. P., Vignon, E., and Dougados, M. (2006). Molecular markers of cartilage breakdown and synovitis at baseline as predictors of structural progression of hip osteoarthritis. The ECHODIAH Cohort. Ann. Rheum. Dis. 65, 354-359.

Nelson, F., Dahlberg, L., Laverty, S. Reiner, A., Pidoux, I., Ionescu, M., Fraser, G. L., Brooks, E., Tanzer, M., Rosenberg, L. C., Dieppe, P., and Robin Poole, A. (1998). Evidence for altered synthesis of type II collagen in patients with osteoarthritis. J. Clin. Invest. 102, 2115-2125.

Nishida, Y., D’Souza, A. L., Thonar, E. J., and Knudson, W. (2000). Stimulation of Hyaluronan metabolism by interleukin-1alpha in human articular cartilage. Arthritis Rheum. 43, 1315-1326.

Reboul, P., Pelletier, J. P., Tardif, G. Cloutier, J. M., and Martel-Pelletier,
J. (1996). The new collagenase, collagenase- 3 , is expressed and synthesized by human chondrocytes but not by synoviocytes. A role in osteoarthritis. J. Clin. Invest. 97, 2011-2019.

Rego, I., Fernández-Moreno, M., Fernández-López, C., GómezReino, J. J., González, A., Arenas, J., and Blanco, F. J. (2010). The role of European mtDNA haplogroups in the prevalence of hip osteoarthritis in Galicia (Northern Spain). Ann. Rheum. Dis. 69, 210-213.

Rego-Pérez, I., Fernández-Moreno, M. Deberg, M., Pértega, S., FernándezLópez, C., Oreiro, N., Henrotin, Y., and Blanco, F. J. (2010). Mitochondrial DNA haplogroups modulate the serum levels of biomarkers in patients with osteoarthritis. Ann. Rheum. Dis. 69, 910-917.

Rego-Pérez, I., Fernández-Moreno, M., Deberg, M., Pértega, S., FernándezLópez, C., Oreiro, N., Henrotin, Y., and Blanco, F. J. (2011). mtDNA haplogroups and serum levels of proteolytic enzymes in patients with osteoarthritis. Ann. Rheum. Dis. 70, 646-652.

Rego-Pérez, I., Fernández-Moreno, M., Fernández-López, C., Arenas, J., and Blanco, F. J. (2008). Mitochondrial DNA haplogroups. Role in the prevalence and severity of knee osteoarthritis. Arthritis Rheum. 58, 2387-2396.

Ruiz-Pesini, E., Lapeña, A. C., DíezSánchez, C., Pérez-Martos, A., Montoya, J., Alvarez, E., Díaz, M., Urriés, A., Montoro, L., López-Pérez, M. J., and Enríquez, J. A. (2000). Human mtDNA haplogroups associated with high or reduced spermatozoa motility. Am. J. Hum. Genet. 67, 682-696.

Spil van, W. E., DeGroot, J., Lems, W. F., Oostveen, J. C., and Lafeber, F. P. (2010). Serum and urinary biochemical markers for knee and hiposteoarthritis: a systematic review applying the consensus BIPED criteria. Osteoarthr. Cartil. 18, 605-612.

Torroni, A., Huoponen, K., Francalacci, P., Petrozzi, M., Morelli, L., Scozzari, R., Obinu, D., Savontaus, M. L., and Wallace, D. C. (1996). Classification of European mtDNAs from an analysis of three European populations. Genetics 144, 1835-1850.

Torroni, A., Petrozzi, M., D’Urbano, L., Sellitto, D., Zeviani, M., Carrara, F., Carducci, C., Leuzzi, V., Carelli, V., Barboni, P., De Negri, A., and Scozzari, R. (1997). Haplotype and phylogenetic analyses suggest that one European-specific mtDNA background plays a role in 
the expression of Leber hereditary optic neuropathy by increasing the penetrance of the primary mutations 11778 and 14484. Am. J. Hum. Genet. 60, 1107-1121.

Valdes, A. M., Hart, D. J., Jones Ka Surdulescu, G., Swarbrick, P., Doyle, D. V., Schafer, A. J., and Spector, T. D. (2004). Association study of candidate genes for the prevalence and progression of knee osteoarthritis. Arthritis Rheum. 50, 2497-2507.

van der Walt, J. M., Dementieva, Y. A., Martin, E. R., Scott, W. K., Nicodemus, K. K., Kroner, C. C., Welsh-Bohmer, K. A., Saunders, A. M., Roses, A. D., Small, G. W., Schmechel, D. E., Murali
Doraiswamy, P., Gilbert, J. R., Haines, J. L., Vance, J. M., and Pericak-Vance, M. A. (2004). Analysis of European mitochondrial haplogroups with Alzheimer disease risk. Neurosci. Lett. 365, 28-32.

van der Walt, J. M., Nicodemus, K. K., Martin, E. R., Scott, W. K., Nance, M. A., Watts, R. L., Hubble, J. P., Haines, J. L., Koller, W. C., Lyons, K., Pahwa, R., Stern, M. B., Colcher, A., Hiner, B. C., Jankovic, J., Ondo, W. G., Allen, F. H. Jr., Goetz, C. G., Small, G. W., Mastaglia, F., Stajich, J. M., McLaurin, A. C., Middleton, L. T., Scott, B. L., Schmechel, D. E., Pericak-Vance, M. A., and Vance, J. M. (2003). Mitochondrial polymorphisms significantly reduce the risk of Parkinson disease. Am. J. Hum. Genet. 72, 804-811.

Wallace, D. C. (1999). Mitochondrial diseases in man and mouse. Science 283, 1482-1488.

Conflict of Interest Statement: The authors declare that the research was conducted in the absence of any commercial or financial relationships that could be construed as a potential conflict of interest.

Received: 10 March 2012; paper pending published: 22 March 2012; accepted: 17 April 2012; published online: 11 May 2012.

Citation: Fernández-Moreno M, SotoHermida A, Oreiro $N$, Pértega $S$,
Fenández-López C, Rego-Pérez I and Blanco FJ (2012) Mitochondrial haplogroups define two phenotypes of osteoarthritis. Front. Physio. 3:129. doi: 10.3389/fphys.2012.00129

This article was submitted to Frontiers in Striated Muscle Physiology, a specialty of Frontiers in Physiology.

Copyright (c) 2012 Fernández-Moreno, Soto-Hermida, Oreiro, Pértega, Fenández-López, Rego-Pérez and Blanco. This is an open-access article distributed under the terms of the Creative Commons Attribution Non Commercial License, which permits non-commercial use, distribution, and reproduction in other forums, provided the original authors and source are credited. 